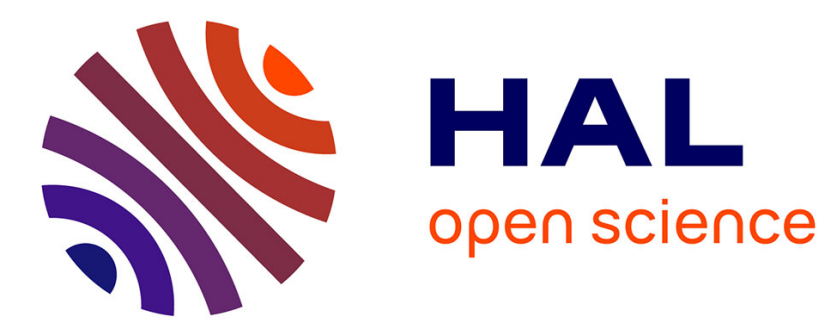

\title{
In vitro biopharmaceutical evaluation of ciprofloxacin/metal cation complexes for pulmonary administration.
}

Julien Brillault, Frédéric Tewes, William Couet, Jean-Christophe Olivier

\section{To cite this version:}

Julien Brillault, Frédéric Tewes, William Couet, Jean-Christophe Olivier. In vitro biopharmaceutical evaluation of ciprofloxacin/metal cation complexes for pulmonary administration.. European Journal of Pharmaceutical Sciences, 2017, 97, pp.92-98. 10.1016/j.ejps.2016.11.011 • inserm-01416565

\section{HAL Id: inserm-01416565 https://www.hal.inserm.fr/inserm-01416565}

Submitted on 14 Dec 2016

HAL is a multi-disciplinary open access archive for the deposit and dissemination of scientific research documents, whether they are published or not. The documents may come from teaching and research institutions in France or abroad, or from public or private research centers.
L'archive ouverte pluridisciplinaire HAL, est destinée au dépôt et à la diffusion de documents scientifiques de niveau recherche, publiés ou non, émanant des établissements d'enseignement et de recherche français ou étrangers, des laboratoires publics ou privés. 


\section{In vitro biopharmaceutical evaluation of}

2 ciprofloxacin/metal cation complexes for pulmonary

3 administration.

$4 \quad$ Brillault $\mathrm{J}^{* \mathrm{a}, \mathrm{b}}$, Tewes $\mathrm{F}^{\mathrm{a}, \mathrm{b}}$, Couet $\mathbf{W}^{\mathrm{a}, \mathrm{b}, \mathrm{c}}$, Olivier $\mathrm{JC}^{\mathrm{a}, \mathrm{b}}$.

5 a Inserm U1070, Pôle Biologie Santé, 1 Rue Georges Bonnet, Poitiers, France

6 b Université de Poitiers, UFR de Médecine et Pharmacie, 15 Rue de l'Hôtel Dieu, Poitiers,

7 France.

$8{ }^{\mathrm{C}} \mathrm{CHU}$ de Poitiers, Service de Toxicologie-Pharmacocinétique, 2 rue de la Milétrie, Poitiers, France.

$9 \quad$ Authors e-mail address: frederic.tewes@univ-poitiers.fr, william.couet@univ-poitiers.fr,

10 jean.christophe.olivier@univ-poitiers.fr

* To whom correspondence should be sent:

E-mail address: julien.brillault@univ-poitiers.fr 
ClP + cation $^{2+} \longrightarrow$ ClP $^{+}$-cation ${ }^{*}$

High

permeability

Low permeability

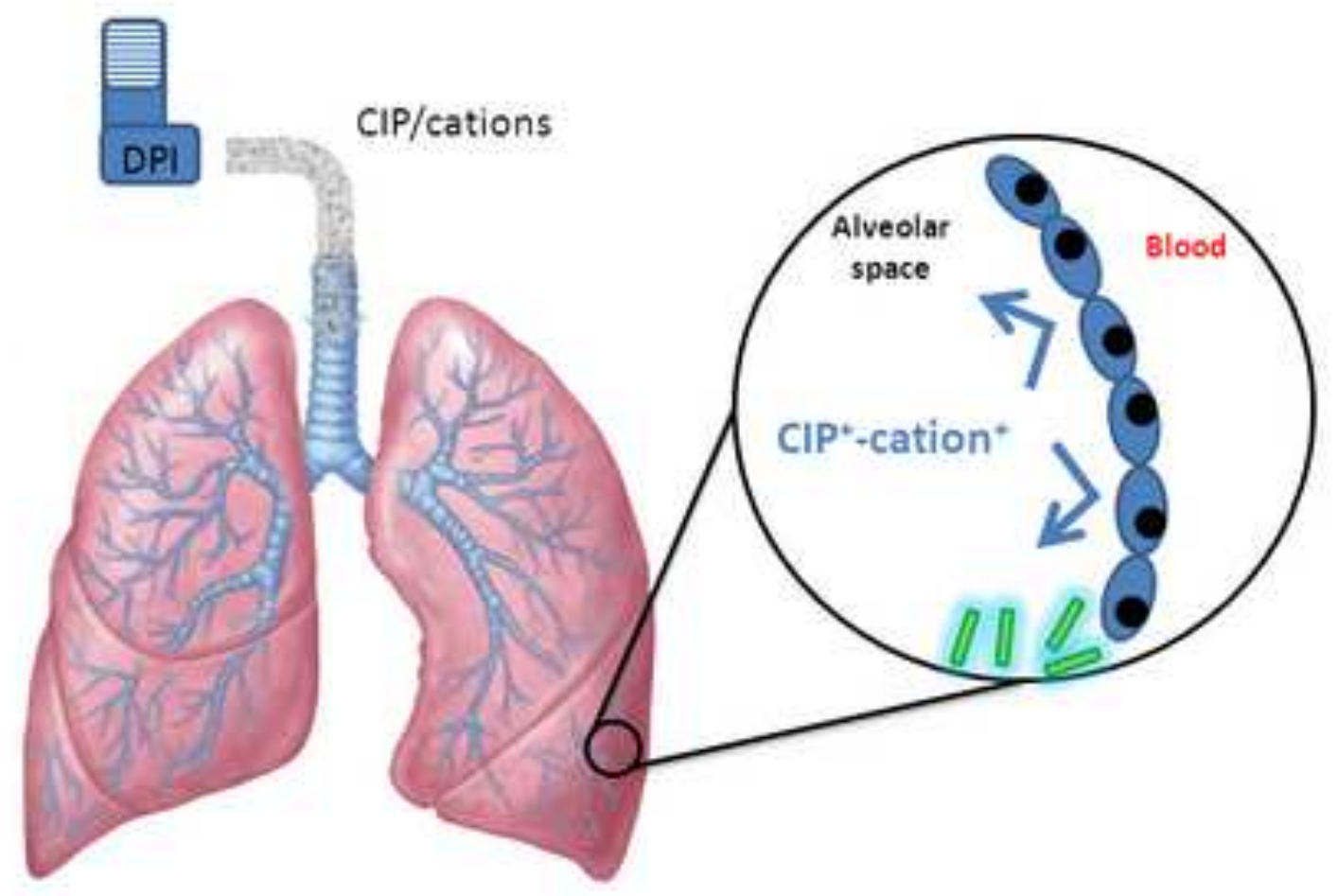




\section{Abstract}

Pulmonary delivery of fluoroquinolones (FQs) is an interesting approach to treat lung infections as it may lead to high local concentrations while minimizing systemic exposure.

However, FQs have a rapid diffusion through the lung epithelium giving the pulmonary route no advantage compared to the oral route. Interactions between FQs and metal cations form complexes which limit the diffusion through the epithelial barrier and would reduce the absorption of FQs and maintain high concentrations in the lung. The effects of this complexation depend on the FQ and the metal cations and optimum partners should be selected through in vitro experiments prior to aerosol drug formulation. In this study, CIP was chosen as a representative $\mathrm{FQ}$ and 5 cations $\left(\mathrm{Ca}^{2+}, \mathrm{Mg}^{2+}, \mathrm{Zn}^{2+}, \mathrm{Al}^{3+}, \mathrm{Cu}^{2+}\right)$ were selected to study the complexation and its effects on permeability, antimicrobial efficacy and cell toxicity. The results showed that the apparent association constants between CIP and cations ranked with the descending order: $\mathrm{Cu}^{2+}>\mathrm{Al}^{3+}>\mathrm{Zn}^{2+}>\mathrm{Mg}^{2+}>\mathrm{Ca}^{2+}$. When a target of $80 \%$ complexation was reached with the adequate concentrations of cations, the CIP permeability through the Calu-3 lung epithelial cells was decreased of $50 \%$. Toxicity of the CIP on the Calu-3 cells, with an EC50 evaluated at $7 \mu \mathrm{M}$, was not significantly affected by the presence of the cations. The minimum inhibitory concentration of CIP for Pseudomonas aeruginosa was not affected or slightly increased in the range of cation concentrations tested, except for $\mathrm{Mg}^{2+}$. In conclusion, permeability was the main parameter that was affected by the metal cation complexation while cell toxicity and antimicrobial activity were not or slightly modified. $\mathrm{Cu}^{2+}$, with the highest apparent constant of association and with no effect on cell toxicity and antimicrobial activity of the CIP, appeared as a promising cation for the development of a controlled-permeability formulation of CIP for lung treatment. 
Keywords: FQ-cation interaction, pulmonary delivery, controlled permeability, ciprofloxacin, Calu-3 cells.

\section{Chemical compounds studied in this article}

Ciprofloxacin (PubChem CID: 2764)

\section{Introduction}

Pulmonary delivery of antibiotics is an interesting approach to treat lung infections as it may lead to high local concentrations with expected high efficiency while minimizing systemic exposure to reduce side effects. This is especially true for drugs that slowly diffuse through the lung epithelium such as colistin or tobramycin (Gontijo et al., 2014b; Marchand et al., 2015). As a matter of facts, the most common antibiotics used in nebulized therapy have also a low lung epithelial permeability, such as tobramycin, colistimethate or aztreonam (Marchand et al., 2010; Marchand et al., 2015, 2016). On the contrary, fluoroquinolones (FQs) such as ciprofloxacin (CIP) have a rapid diffusion through the lung epithelium (Brillault et al., 2010) and following nebulization FQ lung concentrations quickly equilibrate with the plasma concentrations, giving the pulmonary route of administration no advantages compared to the oral route (Gontijo et al., 2014a). However FQs, which are commonly used in patients to treat lung infections by oral administration (Hurley and Smyth, 2012), could benefit from an aerosolized form that would reduce their diffusion through the lung epithelium. Several formulations have been developed to achieve this goal, such as dry powder of CIP but results showed a rapid pulmonary absorption of CIP into the plasma (Stass et al., 2013). Interactions between FQs and metal cations are well-known to decrease the oral absorption and bioavailability (Marchbanks, 1993). FQs form complexes of various 
stoichiometries with various metal cations (Uivarosi, 2013). These complexes have a higher molecular weight with an often ionized molecular structure which limits the diffusion through the intestinal barrier. While this interaction is a disadvantage for the oral route, it may be of great interest for the pulmonary route since it would reduce the absorption of FQs and maintain high concentrations of FQs in the lung. Previous work has shown the feasibility of an inhalable calcium-based microparticle formulation of CIP for pulmonary administration (Tewes et al., 2015). In this study calcium $\left(\mathrm{Ca}^{2+}\right)$ at a high $\mathrm{Ca}^{2+} / \mathrm{CIP}$ mass ratio of 200 decreased the permeability of CIP to $80 \%$ in an in vitro model of the pulmonary epithelium. However, other metal cations and FQs could be used for an optimized controlledpermeability formulation. The optimum partners of FQs and metal cations should be selected through in vitro experiments prior to microparticle formulation, in order to maximize the decrease in FQ permeability, concomitant with a lowest toxicity (i.e. lowest amount of cations and FQ that would be administered to the lung) and high efficiency. Considering the numerous available FQs (about 30 compounds) and also the various metal cations that can bind to FQs $\left(\mathrm{Ca}^{2+}, \mathrm{Mn}^{2+}, \mathrm{Mg}^{2+}, \mathrm{Zn}^{2+}, \mathrm{Fe}^{2+}, \mathrm{Fe}^{3+}, \mathrm{Al}^{3+}, \mathrm{Cu}^{2+}, \mathrm{Ag}^{+}, \mathrm{Co}^{2+}, \mathrm{Ni}^{2+}, \mathrm{Bi}^{3+}\right.$, etc.), several hundreds of possibilities may be considered. It is then necessary to develop first in vitro assays to screen these combinations and predict their interest for the development of new formulations. In this goal, the first point to consider was the ability of FQs and ions to interact together and how it influences the FQ diffusion through the lung.

The second point was to verify if the presence of metal cations and their association with the FQ modified the antimicrobial efficacy and cell toxicity of the antibiotic.

In this study, CIP was chosen as a representative FQ and the 5 five following cations were used to study the complexation with $\mathrm{CIP}: \mathrm{Ca}^{2+}, \mathrm{Mg}^{2+}, \mathrm{Zn}^{2+}, \mathrm{Al}^{3+}$ and $\mathrm{Cu}^{2+}$. Assays were carried out in medium and conditions that mimic the biological characteristics of the lung: 
Interaction between FQs and cations was assayed in a physiological saline buffer, the permeability of CIP in the presence of cations was assayed using the Calu- 3 cell line and the antimicrobial efficacy of CIP in the presence of cations was evaluated against Pseudomonas aeruginosa, a frequent opportunistic infectious agent in the lung. The main purpose of this study was to better understand the interaction between CIP and metal cations in the lung and to help defining the assays needed for a systematic screening of $\mathrm{FQ} /$ metal cation complexes for pulmonary delivery.

\section{Materials \& Methods}

\subsection{Chemicals}

Sodium fluorescein, $\mathrm{ClP}, \mathrm{CaCl}_{2}, 2 \mathrm{H}_{2} \mathrm{O} ; \mathrm{MgCl}_{2}, 4.5 \mathrm{H}_{2} \mathrm{O} ; \mathrm{ZnSO}_{4}, 7 \mathrm{H}_{2} \mathrm{O} ; \mathrm{CuSO}_{4}, 5 \mathrm{H}_{2} \mathrm{O} ; \mathrm{Al}(\mathrm{OH})_{3}$; MOPS, TRIS and HEPES were obtained from Sigma-Aldrich. HPLC-grade acetonitrile was purchased from VWR International (Fontenay sous Bois, France). Mueller Hinton II agar and Mueller Hinton II Broth (cation adjusted) were from Becton Dickinson (Le Pont-de-Claix, France). All other reagents were of analytical grade.

\subsection{Apparent constant of association (K)}

To study the interaction between FQs and metal cations in medium having ion composition and $\mathrm{pH}$ close to biological samples such as the epithelial lining fluid (ELF) of the lung alveoli, $\mathrm{ClP}$ was incubated in saline solution $(\mathrm{NaCl}$ and $\mathrm{KCl})$ at $\mathrm{pH}=7.4$. To assess the possible interaction between CIP and buffers, HEPES, MOPS or TRIS buffer was added to a $30 \mu \mathrm{M} \mathrm{CIP}$ solution in water at different concentrations $(0,1,2.5,7.5$ and $10 \mathrm{mM})$ and $\mathrm{pH}$ was adjusted to 7.4 with $1 \mathrm{M}$ sodium hydroxide. One $\mathrm{ml}$ of each solution was placed in 24 well plates and 
111 fluorescence intensity emission spectrum of CIP was recorded at room temperature with a

112 plate reader $(\lambda \mathrm{exc}=274 \mathrm{~nm}$ and $\lambda$ em ranging from 360 to $500 \mathrm{~nm}$; VarioskanFlash, Thermo

113 Scientific, Villebon sur Yvette, France). MOPS and Tris buffers shifted and lowered the

114 spectrum respectively, HEPES buffer did not affect the CIP fluorescence from 360 to $500 \mathrm{~nm}$

115 with a concentration up to $10 \mathrm{mM}$ (data not shown). Moreover, HEPES is generally

116 considered a non-complexing buffer and is suitable for use in solutions with metal ions

117 (Ferreira et al., 2015). This buffer was then chosen for all the following experiments.

118 Fluorescence emission spectrum of CIP in the presence of increasing concentrations of the

119 different cations did not show a shift of the maximum emission wavelength. The set of 274

120 and $408 \mathrm{~nm}$ for the excitation and emission wavelengths was chosen for all the titration

121 experiments. Fluorescence titration profiles were obtained by adding cation solutions with

122 concentrations ranging from 500 to $10^{5} \mu \mathrm{M}$ for calcium and magnesium ions, from 15 to 500

$123 \mu \mathrm{M}$ for zinc ions and from 15 to $150 \mu \mathrm{M}$ for copper and aluminum ions to a $3 \mu \mathrm{M}$ CIP

124 solution. Solutions contained $5.3 \mathrm{mM} \mathrm{KCl}$ and were maintained at constant pH 7.4 with 10

$125 \mathrm{mM}$ HEPES and adjusted with $\mathrm{NaCl}$ to a constant ionic strength (155 mM for $\mathrm{Mg}^{2+}, \mathrm{Zn}^{2+}, \mathrm{Al}^{3+}$,

$126 \mathrm{Cu}^{2+}$ and $1205 \mathrm{mM}$ for $\left.\mathrm{Ca}^{2+}\right)$. The final volume of each sample was $1 \mathrm{ml}$ and fluorescence was

127 recorded using the VarioskanFlash plate reader. Binding isotherm equations for 1:1 and 2:1

128 complexes were built to describe the data according to Hargove et al. (Hargrove et al., 2010).

129 Equations and mathematical development can be found in the Appendix A. The

130 experimental data were fitted with the two models (1:1 and 2:1) and the comparison was

131 evaluated with the Akaike's information criteria (AIC).

132 2.3. Apparent permeability (Papp) of CIP in the presence of metal cations

$133 \quad$ 2.3.1. Calu-3 cell culture 
Calu-3 cells were purchased from the American Type Culture Collection (Manassas, VA, USA). The cells were cultured in DMEM/Ham's F12 (1/1) supplemented with L-glutamine (2 mM) and $10 \%$ foetal calf serum (PAN-Biotech $\mathrm{GmbH}$, Aidenbach, Germany) and incubated at $37^{\circ} \mathrm{C}$ under $90-95 \%$ of relative humidity and $5 \% \mathrm{v} / \mathrm{v}$ of $\mathrm{CO}_{2}$ in air. The Calu-3 cells at passages $50-$ 60 were seeded at a density of $15 \times 10^{4}$ cells $/ \mathrm{cm}^{2}$ onto 12 -well plate Transwell inserts (Corning Transwell Clear PET membrane $0.4 \mu \mathrm{m}$, Thermofischer Scientific). The cells were cultured under air-interface conditions for 15 days. The growth medium in the basolateral compartment $(1.5 \mathrm{ml})$ was replaced by fresh medium every other day.

\subsubsection{Transport experiments}

Transport experiments were conducted in apical-to-basolateral directions as described elsewhere (Brillault et al., 2010). Briefly, on study day the Calu-3 monolayers were quickly rinsed with the transport medium (TM: $\mathrm{NaCl} 134 \mathrm{mM}, \mathrm{KCl} 5.3 \mathrm{mM}$, glucose $5.5 \mathrm{mM}, \mathrm{CaCl}_{2} 1.3$ $\mathrm{mM}, \mathrm{MgCl}_{2} 1 \mathrm{mM}$, buffered with $10 \mathrm{mM}$ HEPES and adjusted to $\mathrm{pH}$ 7.4) and then incubated for $30 \mathrm{~min}$ in TM. This transport medium is a modified formula of the classical HBSS medium without bicarbonate or phosphate known to form complexes with the metal ions. Following the equilibration period, the TM in the donor compartment (apical side) was replaced by fresh TM containing $50 \mu \mathrm{M}$ of CIP with $0,5,10,50$ or $100 \mathrm{mM} \mathrm{Mg}^{2+}$. After 60 min of incubation at $37^{\circ} \mathrm{C}$, sample aliquots were taken from the acceptor compartment (basolateral side). Apparent permeability (Papp) was calculated using eqn (1) where $Q$ is the amount of $\mathrm{CIP}$ in the acceptor compartment after a time $\Delta \mathrm{t}, \mathrm{S}$ is the insert membrane surface $(1.12$ $\left.\mathrm{cm}^{2}\right),[\mathrm{CIPo}]$ is the initial CIP concentration in the donor compartment.

$$
\text { Papp }=\frac{Q}{[C I P o] . \Delta t . S}
$$


156 Papp versus $\mathrm{Mg}^{2+}$ concentration data were analysed with the following equation (eqn 2).

$157 \%$ of Papp $=100-\frac{(100-P a p p \text { Min }) \cdot[X]^{n H}}{E C 50^{n H}+[X]^{n H}}$

158 Where Papp ${ }_{\text {Min }}$ is the low plateau of Papp, $[\mathrm{X}]$ the $\mathrm{Mg}^{2+}$ concentration, EC50 the $\mathrm{Mg}^{2+}$

159 concentration necessary to get $50 \%$ of the maximum effect (100-Papp Min) and $\mathrm{nH}$ the Hill

160 number. In a second experiment, Papp were determined after cells were incubated in TM

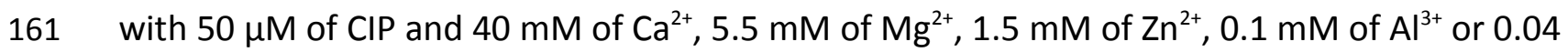

$162 \mathrm{mM}$ of $\mathrm{Cu}^{2+}$ for a 60 min incubation period before sampling in the acceptor compartment.

163 Following the transport studies, routine controls of the monolayer integrity were performed

164 using sodium fluorescein. Briefly, the monolayers were rinsed with TM, fresh TM was added

165 in the basolateral side and a solution of sodium fluorescein in TM $(10 \mu \mathrm{g} / \mathrm{ml})$ was poured in

166 the apical side. The inserts were incubated and samples were taken after 60 min from the

167 acceptor compartment. A threshold $P_{\text {app }}$ value of $0.7 \times 10^{-6} \mathrm{~cm} . \mathrm{s}^{-1}$ for fluorescein was

168 retained for the tight junction integrity rejection parameter for all experiments. This

169 corresponds to the transfer of less than $0.5 \%$ of the initial amount in the apical compartment

170 (Brillault et al., 2010).

\section{$171 \quad$ 2.3.3. CIP and sodium fluorescein assay}

172 CIP was assayed using a HPLC method with fluorometric detection ( $\lambda$ exc $=280 \mathrm{~nm}$; $\lambda$ em $=460$

$173 \mathrm{~nm}$ ) using a Jasco FP-920 fluorescence detector (Jasco France, Lisses, France). The stationary

174 phase was an XTerra MS C18 column, $5 \mu \mathrm{m}, 100 \times 2.1 \mathrm{~mm}$ (Waters, Milford, MA). The mobile

175 phase (flow rate: $0.25 \mathrm{ml} / \mathrm{min}$ using a Hitachi L-2130 pump, Hitachi High technologies Co.,

176 Berkshire, UK) consisted of a 20:80 (v:v) mixture of acetonitrile and water containing $0.1 \%$

177 formic acid and $0.2 \%$ heptane sulfonic acid. Samples, standards ( 7 levels with concentrations 
ranging from 1.56 to $50 \mathrm{ng} / \mathrm{ml}$ ) and quality controls $(3.12,12.5$ and $37.5 \mathrm{ng} / \mathrm{ml}$ ) prepared in the same solvent were injected (75 $\mu$ l using a Hitachi L-2200 autosampler) and eluted over a run time of $6.5 \mathrm{~min}$. The precision and accuracy were less than $15 \%$ for the 3 quality control concentrations. Controls with various concentrations of CIP and cations were assayed to ensure that the presence of cations did not interfere with the analysis of CIP.

Fluorescein concentrations in TM were measured using the VarioskanFlash plate reader with the excitation and emission wavelengths set at $490 \mathrm{~nm}$ and $530 \mathrm{~nm}$, respectively.

\subsection{Cytotoxicity assay}

Calu-3 cells were seeded in 96 well plates at the density of 5000 cells/well. Incubation medium (100 $\mu \mathrm{l}$ ) was Gibco MEM (Thermo Fisher Scientific) supplemented with 5\% (v/v) foetal calf serum. CIP and ions solutions were prepared at concentrations necessary to achieve $80 \%$ of complex. Namely, $150 \mu \mathrm{M}$ of CIP were mixed with $40.1 \mathrm{mM}$ of $\mathrm{Ca}^{2+}, 5.6 \mathrm{mM}$ of $\mathrm{Mg}^{2+}, 1.6 \mathrm{mM}$ of $\mathrm{Zn}^{2+}, 0.17 \mathrm{mM}$ of $\mathrm{Al}^{3+}$ or $0.125 \mathrm{mM}^{2}$ of $\mathrm{Cu}^{2+}$. The cells were then incubated with a serial dilution of these solutions or the CIP alone with concentrations ranging from 0.3 to $150 \mu \mathrm{M}$ and the plates were returned to the incubator. Control cells were incubated with ions alone with serial dilution from 100 to $0.05 \mathrm{mM}$ for $\mathrm{Ca}^{2+}$ and $\mathrm{Mg}^{2+}$ and from 5 to 0.0025 $\mathrm{mM}$ for $\mathrm{Zn}^{2+}, \mathrm{Al}^{3+}$ and $\mathrm{Cu}^{2+}$. Following a $24 \mathrm{~h}$ incubation time, the incubation medium was removed and replaced with HBSS medium and cell viability was evaluated with a MTS assay kit (CellTiter $96^{\circledR}$ AQueous One Solution Cell Proliferation Assay from Promega, Charbonnières-les-Bains, France) according to the manufacturer protocol. The linearity of the response was verified thanks to preliminary experiments. Data were analysed with the following equation (eqn 3). 
$200 \%$ of viability $=$ Top $-\frac{(\text { Top-Bottom }) \cdot[X]^{n H}}{E C 50^{n H}+[X]^{n H}}$

201

202

203

204

205

206

207

208

209

210

211

212

213

214

215

216

217

where $[\mathrm{X}]$ is the concentration of CIP or ions, Top and Bottom are plateaus in the units of the

$\mathrm{Y}$ axis, EC50 is the concentration that gives half of the total effect (Top-Bottom) and $\mathrm{nH}$ is the Hill number.

\subsection{MIC assay}

The effect of cation $\left(\mathrm{Mg}^{2+}, \mathrm{Ca}^{2+}, \mathrm{Al}^{3+}, \mathrm{Zn}^{2+}, \mathrm{Cu}^{2+}\right)$ concentrations on the CIP antibacterial activity was assessed by measuring the apparent CIP minimum inhibitory concentration (MIC) against Pseudomonas aeruginosa PAO1 (CIP 104116, Institut Pasteur, Paris, France).

Bacteria were stored at $-80^{\circ} \mathrm{C}$. One day before the experiment, they were grown on MuellerHinton II agar for $24 \mathrm{~h}$ at $37^{\circ} \mathrm{C}$. Prior to MIC test, the strains were grown to logarithmic phase in fresh Mueller-Hinton broth II (MHB) for 2-3 hours and then adjusted to 0.5 McFarland standards. The MIC test was performed using the broth microdilution method: The adjusted cultures were diluted 100-times in MHB containing cations, CIP or both and $100 \mu \mathrm{l}$ of these bacterial suspensions were seeded in 96 well plates. CIP concentrations were 8, 4, 2, 1, 0.5, $0.25,0.125,0.063,0.031,0 \mu \mathrm{g} / \mathrm{ml} \mathrm{Mg}^{2+}$ concentrations were $20,10,5,2,1,0.5,0 \mathrm{mM} . \mathrm{Ca}^{2+}$ concentrations were $100,50,20,10,5,2,1,0.5,0 \mathrm{mM} . \mathrm{Zn}^{2+}$ concentrations were $1,0.5,0.1$, $0.05,0.02,0.01,0 \mathrm{mM} . \mathrm{Al}^{3+}$ and $\mathrm{Cu}^{2+}$ concentrations were $0.1,0.05,0.02,0.01,0.005,0 \mathrm{mM}$. The growth of bacterial cultures at $37^{\circ} \mathrm{C}$ was determined after 18 hours by monitoring the optical density of the culture at $600 \mathrm{~nm}$ using the VarioskanFlash plate reader. Controls without bacteria were made to check the absence of contamination of MHB and to evaluate the effect of the cations on the absorbance reading at $600 \mathrm{~nm}$. Controls without CIP were made to assess the effect of the cations on bacterial growth. 


\subsection{Statististical analysis}

Data analysis and modeling were performed using GraphPad Prism version 5.02 for Windows (GraphPad Software, San Diego California USA, www.graphpad.com).

\section{Results}

\subsection{Apparent constants of association}

Titration curves of $\mathrm{CIP}$ with $\mathrm{Mg}^{2+}, \mathrm{Ca}^{2+}, \mathrm{Zn}^{2+}, \mathrm{Al}^{3+}$ and $\mathrm{Cu}^{2+}$ ions were made in HEPES buffered saline solutions (Figure 1). Increasing the concentration of $\mathrm{Ca}^{2+}, \mathrm{Mg}^{2+}$ and $\mathrm{Zn}^{2+}$ resulted in an increase in the total fluorescence, while with $\mathrm{Al}^{3+}$ and $\mathrm{Cu}^{2+}$ the total fluorescence was quenched. The equation corresponding to a 1:1 complex model fitted the data well for all the ions with a satisfactory accuracy for the estimated apparent constant of association (Table 1). On the other hand, the equation from the 2:1 complex model resulted in a very broad estimation of the parameters and higher AIC values (data not shown). This suggested a 1:1 (CIP:metal cation) complex stoichiometry. The estimated apparent association constants ranked with the descending order: $\mathrm{Cu}^{2+}>\mathrm{Al}^{3+}>\mathrm{Zn}^{2+}>\mathrm{Mg}^{2+}>\mathrm{Ca}^{2+}$, with almost a 9000 fold ratio between the minimum and maximum values (Table 1).

\subsection{Influence of complexation on Calu-3 cell layer permeability}

In a preliminary experiment, $\mathrm{Mg}^{2+}$ was chosen to test the influence of the ion concentration on the apical to basolateral permeability of CIP through the Calu-3 cell model. In the control conditions where no magnesium was added to the transport medium, the Papp was $0.34 \pm$ $0.02 \times 10^{-6} \mathrm{~cm} / \mathrm{s}$. The results on figure $2 \mathrm{~A}$ showed a decrease in the CIP Papp dependent on 
the concentration of $\mathrm{Mg}^{2+}$. As estimated by the modeling, $6.7 \mathrm{mM}$ of added magnesium

244 reduced the Papp to $50 \%$ of the control and a plateau was reached at $11.5 \%$ of the control Papp $\left(0.04 \times 10^{-6} \mathrm{~cm} / \mathrm{s}\right)$. According to the mass balance equations from 1:1 model (Appendix A) and to the apparent constant of association determined in table 1, the percentage of complexation of $\mathrm{ClP}$ by $\mathrm{Mg}^{2+}$ was calculated and plotted against the Papp (Figure 2B). These data were modeled with eqn 2 and showed that it is necessary to form $86 \%$ of complexation to reduce the Papp of $50 \%$. Since the complexation apparently correlated with the decrease in permeability, the transport of CIP was assayed at concentrations of metal cations necessary to reach the same level of complexation. As seen with the $\mathrm{Mg}^{2+}$, a high level of complexation is needed to induce a significant decrease in permeability, but high concentrations of ions, as for $\mathrm{Ca}^{2+}$ would lead to hypertonic and deleterious conditions for the cells. For these reasons, a target of $80 \%$ complexation was chosen for the next experiment and theoretical ion concentrations were calculated for $\mathrm{Ca}^{2+}, \mathrm{Mg}^{2+}, \mathrm{Zn}^{2+}, \mathrm{Cu}^{2+}$ and $\mathrm{Al}^{3+}$. Thus the cells were incubated in the presence of $50 \mu \mathrm{M}$ of CIP and $40 \mathrm{mM}$ of $\mathrm{Ca}^{2+}, 5.5$ $\mathrm{mM}$ of $\mathrm{Mg}^{2+}, 1.5 \mathrm{mM}$ of $\mathrm{Zn}^{2+}, 0.1 \mathrm{mM}$ of $\mathrm{Al}^{3+}$ or $0.04 \mathrm{mM}^{2} \mathrm{Cu}^{2+}$. Results confirmed that such cation concentrations leaded to a decrease in CIP permeability close to 50\% (Figure 3).

\subsection{Cytotoxicity assay}

As shown in figure 4A and table 2, ions may be classified into two groups according to their cytotoxicity: the first group (low toxicity) includes $\mathrm{Mg}^{2+}$ and $\mathrm{Ca}^{2+}$ with an estimated EC50 at $36 \times 10^{3}$ and $131 \times 10^{3} \mu \mathrm{M}$, respectively; the second group (higher toxicity) includes $\mathrm{Zn}^{2+}, \mathrm{Al}^{3+}$ and $\mathrm{Cu}^{2+}$ with EC50 close to $1 \times 10^{3} \mu \mathrm{M}$. Cytotoxicity of the CIP was evaluated in the presence of cations. The highest CIP concentration was $150 \mu \mathrm{M}$ and ion concentrations were chosen to reach $80 \%$ complexation. For $\mathrm{Cu}^{2+}, \mathrm{Mg}^{2+}, \mathrm{Al}^{3+}$ and $\mathrm{Ca}^{2+}$, the concentrations were several 
times lower than their respective EC50 and for $\mathrm{Zn}^{2+}$ equal to its EC50 (Table 2). Thus, the presence of ions at concentrations forming $80 \%$ complexes with CIP should not increase the cell toxicity of the CIP. As shown in figure 4B and table 2, the EC50 of the CIP over the Calu-3, which was evaluated to be $7 \mu \mathrm{M}$, was not apparently affected by the presence of these ions.

\subsection{MIC assay}

The influence of the cations was also tested on the antibacterial effect of CIP against $P$. aeruginosa. In the presence of the ions alone at all concentrations tested, the bacterial growth was similar to the control (data not shown). The MIC of CIP was $0.25 \mu \mathrm{g} / \mathrm{ml}$. In the presence of $\mathrm{Ca}^{2+}$ or $\mathrm{Mg}^{2+}$ the MIC of CIP was increased from an ion concentration of $5 \mathrm{mM}$ (33\% of complexation) and $2 \mathrm{mM}$ (50\% of complexation) onwards, respectively (Figure $5 \mathrm{~A}$ ). In the presence of $\mathrm{Zn}^{2+}$, the MIC was unchanged up to a concentration of $500 \mu \mathrm{M}(50 \%$ of complexation) where it decreased of one level. The MIC remained unchanged for $\mathrm{Al}^{3+}$ and $\mathrm{Cu}^{2+}$, except at $50 \mu \mathrm{M}$ for copper (98\% of complexation) (Figure $5 \mathrm{~B}$ ).

\section{Discussion}

Interactions between FQs and metal cations have been widely studied and it has been shown that the presence of metal cations affects both solubility and membrane permeability of FQs (Stojkovic et al., 2014; Zakelj et al., 2007). The consequence for the oral route is a decrease in their bioavailability. However for the pulmonary route, low permeability with high solubility could be of great advantage for antibacterial lung treatment since it would increase the drug residence time in the lung and lower the systemic side effects.

Antimicrobial efficacy is also sometimes affected in a positive or negative way (Uivarosi, 
2013). The mechanisms underlying these effects are not clearly understood and may involve

289

290

291

292

293

294

295

296

297

298

299

300

301

302

303

304

FQs electric charge, molecular weight, lipophilicity, membrane permeability and/or binding with their bacterial enzymatic target. These modifications of the bioavailability or efficacy are not predictable and needs to be evaluated. In this work in vitro assays have been developed to study the interaction between $\mathrm{CIP}$ and $\mathrm{Mg}^{2+}, \mathrm{Ca}^{2+}, \mathrm{Zn}^{2+}, \mathrm{Al}^{3+}, \mathrm{Cu}^{2+}$.

Apparent constants of stability between metal cations and CIP have been evaluated in biological conditions. Since the ionic composition of the ELF is not known, a simple saline buffer ( $\mathrm{pH}$ 7.4) containing extra-cellular concentrations of sodium, potassium and chloride was chosen. In this medium the apparent association constants $\mathrm{K}$ ranked as $\mathrm{Cu}^{2+}>\mathrm{Al}^{3+}>\mathrm{Zn}^{2+}>\mathrm{Mg}^{2+}>\mathrm{Ca}^{2+}$ (Table 1). These results are in accordance with previous works with an equivalent ranking where the highest interactions were obtained with $\mathrm{Al}^{3+}$ and $\mathrm{Cu}^{2+}(\mathrm{Ma}$ et al., 1997; Seedher and Agarwal, 2010). Interestingly, for $\mathrm{Ca}^{2+}, \mathrm{Mg}^{2+}$ and $\mathrm{Zn}^{2+}$ the interactions increased the fluorescence intensity of the solutions while for $\mathrm{Cu}^{2+}$ and $\mathrm{Al}^{3+}$ the interactions resulted in a strong decrease of the fluorescence. Similar results had been obtained previously, where $\mathrm{Cu}^{2+}$ strongly decreased the CIP fluorescence while $\mathrm{Mg}^{2+}$ increased it (Drevensek et al., 2003). This may be due to different sites of interaction on the CIP molecule, which has two main sites of metal chelate formation: one on the carbonyl and carboxyl groups and the second on the piperazin group (Uivarosi, 2013). Quinolone-metal cation chelates may be synthetized as $1: 1,2: 1$ or $3: 1$ (FQ:metal cation) complexes depending on the cation, $\mathrm{pH}$ and the synthesis process. Here, the titration of CIP in biological conditions showed a spontaneous interaction with metal cations as 1:1 complexes as shown by the modeling of the data (Figure 1). To evaluate if these interactions could affect CIP permeability across the epithelial cells of the lung, CIP apparent permeability was assessed with the Calu-3 cell model in the presence of the different cations (Figure 2 and 3). It should 
be noted that $\mathrm{Mg}^{2+}$ and $\mathrm{Ca}^{2+}$ concentrations of about $1 \mathrm{mM}$ are needed for the cell layer

integrity since the intercellular junctions that seals the cells together need these two cations to be effective. Thus the transport experiments were made in conditions where $\mathrm{Ca}^{2+}$ and $\mathrm{Mg}^{2+}$ were already present and would be responsible for $11 \%$ and $41 \%$ complexation of CIP, respectively. Since the concentration of $\mathrm{Mg}^{2+}$ in plasma is close to $1 \mathrm{mM}$, this also would suggest that in biological fluids CIP is in part present as a $\mathrm{Mg}^{2+}$ complex (Jahnen-Dechent and Ketteler, 2012). This might be also the case in the ELF of the alveolar space. For the same reason, in the bacteria cytoplasm where the concentration of free $\mathrm{Mg}^{2+}$ is about $1-2 \mathrm{mM}$ (Alatossava et al., 1985), CIP is expected to be present inside the cell mostly as a CIP: $\mathrm{Mg}^{2+}$ complex. Nevertheless the results showed a strong correlation between metal cation concentration and decrease in CIP apparent permeability through the cells. With $\mathrm{Mg}^{2+}, \mathrm{a}$ maximum decrease in permeability of about $90 \%$ was observed in conditions were the CIP is almost completely complexed. It is not known whether the $10 \%$ remaining apparent flux of CIP is due to the diffusion of the CIP: $\mathrm{Mg}^{2+}$ complex or of the free CIP. The permeability experiments with the other cations showed that the apparent association constant is useful to predict the effect of the interaction over the cell permeability. The complexation of $80 \%$ of the CIP affected the apparent CIP permeability with the same extent, whatever the nature of the metal cations. This result suggests that only the electric charges brought by the metal cations are responsible for the decrease in permeability. Indeed, in the case of a 1:1 CIP:metal cation interaction, a bicationic complex $\mathrm{CIP}^{+}-\mathrm{M}^{+}$appears, while $\mathrm{CIP}$ is an overall uncharged zwitterionic molecule at $\mathrm{pH}$ 7. It is also unlikely that the extra molecular weight brought by the cations would influence the CIP diffusion since they represent only 7 to $19 \%$ of the CIP MW. The apparent association constants varied from 100 to $900000 \mathrm{M}^{-1}$ for $\mathrm{Ca}^{2+}$ and $\mathrm{Cu}^{2+}$ respectively (Table 1). This difference has huge consequences on the amount of 
cations necessary for the complexation of the CIP. For instance, if a pharmaceutical pulmonary drug formulation is designed to deliver in the ELF $1 \mu \mathrm{g} / \mathrm{ml}(3 \mu \mathrm{M})$ of CIP, which is in the range of MIC for the majority of $P$. aeruginosa from environmental sites and patients (Macdonald et al., 2010), the ion concentration in the ELF needed to reach $80 \%$ of complexation would be $1600 \mu \mathrm{g} / \mathrm{ml}$ for $\mathrm{Ca}^{2+}$ and only $0.4 \mu \mathrm{g} / \mathrm{ml}$ for $\mathrm{Cu}^{2+}$. Metal cations are known to be potentially toxic to the cells mainly through reactive oxygen species generation and then increased intra-cellular oxidative stress (Stohs and Bagchi, 1995). Cytotoxicity studies showed that for cations with the highest association constant with $\mathrm{CIP}\left(\mathrm{Cu}^{2+}, \mathrm{Al}^{3+}\right.$ and $\mathrm{Zn}^{2+}$ ), the relative cell toxicity was about 100 times higher than for $\mathrm{Mg}^{2+}$ and $\mathrm{Ca}^{2+}$ (Figure 4 and Table 2). However, in the hypothesis of a pulmonary drug formulation that could deliver in the lining fluid of the alveoli a CIP concentration 50 times higher than the MIC for $P$. Aeruginosa (i.e. $150 \mu \mathrm{M}$ ), the corresponding concentration of cations necessary to achieve complexation of most of the CIP is several times lower than the EC50 of the cations for the cell toxicity. Thus, the higher toxicity of $\mathrm{Cu}^{2+}, \mathrm{Al}^{3+}$ or $\mathrm{Zn}^{2+}$ may be counterbalanced by the lower concentration needed for complexation compared to that of $\mathrm{Ca}^{2+}$ and $\mathrm{Mg}^{2+}$. Several articles have reported that FQ:metal cation complexes had a limited or no effect on the antibacterial activity. For instance, complexes of CIP with $\mathrm{Zn}^{2+}$ or $\mathrm{Cu}^{2+}$ have been shown to have no influence on the MIC against S. aureus, P. aeruginosa or K. pneumoniae (LópezGresa et al., 2002) while complexes of levofloxacin with $\mathrm{Mg}^{2+}$ slightly decreased the antibacterial activity with the same strains (Drevenšek et al., 2006). Here MIC assays have been done to evaluate this influence over $P$. aeruginosa (Figure 5). The growth medium for the bacteria already contains limited amounts of $\mathrm{Ca}^{2+}$ and $\mathrm{Mg}^{2+}(0.5$ and $0.4 \mathrm{mM}$, respectively). However, due to the low concentrations and the weak constants of association of these two ions, their influence can be considered negligible. None or slight increase in 
MIC have been shown in the range of cation concentration tested, except for $\mathrm{Mg}^{2+}$ at $10 \mathrm{mM}$

361

362

363

364

365

366

367

where its presence greatly decreased the antimicrobial activity of CIP. This is in agreement with a previous study with sparfloxacin, ciprofloxacin, norfloxacin and pefloxacin where $\mathrm{Mg}^{2+}$ was shown to decrease the antibacterial activity of the FQs in correlation with a lower uptake into the bacteria. These results suggested that $\mathrm{Mg}^{2+}$ impaired the CIP uptake into the bacteria (Lecomte et al., 1994).

In conclusion, this work showed the influence of metal cations on permeability and antimicrobial activity of the CIP in the goal of pulmonary administration. Permeability was the main parameter that was affected by the metal cation complexation while cell toxicity or antimicrobial activity were not or slightly modified, as shown by the in vitro experiments. While $\mathrm{Al}^{3+}$ is suspected of brain toxicity, $\mathrm{Cu}^{2+}$ seems to be an interesting cation for the development of a controlled-permeability formulation of CIP for lung treatment and further studies will evaluate the pharmacokinetics of CIP after lung administration of CIP: $\mathrm{Cu}^{2+}$ loaded microparticles. More generally, in the goal of selecting the best FQ:metal cation couple for lung delivery formulation, the association constant between FQ and metal cation should be estimated first since this parameter is of great influence on permeability. Lipophilicity of the FQ was not addressed in this study but it should also be taken into account because the effect of complexation over permeability could have a major effect for the most lipophilic drugs such as moxifloxacin, grepafloxacin or pefloxacin. Toxicity and antimicrobial activity should be then investigated with the most interesting couples. Further studies will focus on the effects of metal cation interactions with FQs of different lipophilicities and on in vivo pharmacokinetic evaluations of novel FQ-metal cation formulations. 
Alatossava, T., Jutte, H., Kuhn, A., Kellenberger, E., 1985. Manipulation of intracellular magnesium content in polymyxin B nonapeptide-sensitized Escherichia coli by ionophore A23187. Journal of bacteriology 162, 413-419.

Brillault, J., De Castro, W.V., Couet, W., 2010. Relative contributions of active mediated transport and passive diffusion of fluoroquinolones with various lipophilicities in a Calu-3 lung epithelial cell model. Antimicrobial agents and chemotherapy 54, 543-545.

Drevenšek, P., Košmrlj, J., Giester, G., Skauge, T., Sletten, E., Sepčić, K., Turel, I., 2006. X-Ray crystallographic, NMR and antimicrobial activity studies of magnesium complexes of fluoroquinolones - racemic ofloxacin and its S-form, levofloxacin. Journal of Inorganic Biochemistry 100, 1755-1763.

Drevensek, P., Turel, I., Poklar Ulrih, N., 2003. Influence of copper(II) and magnesium(II) ions on the ciprofloxacin binding to DNA. J Inorg Biochem 96, 407-415.

Ferreira, C.M.H., Pinto, I.S.S., Soares, E.V., Soares, H.M.V.M., 2015. (Un)suitability of the use of pH buffers in biological, biochemical and environmental studies and their interaction with metal ions - a review. RSC Advances 5, 30989-31003.

Gontijo, A.V., Brillault, J., Gregoire, N., Lamarche, I., Gobin, P., Couet, W., Marchand, S., 2014a. Biopharmaceutical characterization of nebulized antimicrobial agents in rats: 1 . Ciprofloxacin, moxifloxacin, and grepafloxacin. Antimicrobial agents and chemotherapy 58, 3942-3949.

Gontijo, A.V., Gregoire, N., Lamarche, I., Gobin, P., Couet, W., Marchand, S., 2014b.

Biopharmaceutical characterization of nebulized antimicrobial agents in rats: 2 . Colistin. Antimicrobial agents and chemotherapy 58, 3950-3956.

Hargrove, A.E., Zhong, Z., Sessler, J.L., Anslyn, E.V., 2010. Algorithms for the determination of binding constants and enantiomeric excess in complex host : guest equilibria using optical measurements. New journal of chemistry = Nouveau journal de chimie 34, 348-354.

Hurley, M., Smyth, A., 2012. Fluoroquinolones in the treatment of bronchopulmonary disease in cystic fibrosis. Therapeutic advances in respiratory disease 6, 363-373.

Jahnen-Dechent, W., Ketteler, M., 2012. Magnesium basics. Clinical Kidney Journal 5, i3-i14. Lecomte, S., Baron, M.H., Chenon, M.T., Coupry, C., Moreau, N.J., 1994. Effect of magnesium complexation by fluoroquinolones on their antibacterial properties. Antimicrobial agents and chemotherapy 38, 2810-2816.

López-Gresa, M.P., Ortiz, R., Perelló, L., Latorre, J., Liu-González, M., García-Granda, S., Pérez-Priede, M., Cantón, E., 2002. Interactions of metal ions with two quinolone antimicrobial agents (cinoxacin and ciprofloxacin): Spectroscopic and X-ray structural characterization. Antibacterial studies. Journal of Inorganic Biochemistry 92, 65-74.

Ma, H.H., Chiu, F.C., Li, R.C., 1997. Mechanistic investigation of the reduction in antimicrobial activity of ciprofloxacin by metal cations. Pharmaceutical research 14, 366-370.

Macdonald, D., Cuthbertson, L., Doherty, C., Campana, S., Ravenni, N., Taccetti, G., Govan, J.R., 2010. Early Pseudomonas aeruginosa infection in individuals with cystic fibrosis: is susceptibility testing justified? The Journal of antimicrobial chemotherapy 65, 2373-2375.

Marchand, S., Gobin, P., Brillault, J., Baptista, S., Adier, C., Olivier, J.C., Mimoz, O., Couet, W., 2010. Aerosol therapy with colistin methanesulfonate: a biopharmaceutical issue illustrated in rats. Antimicrobial agents and chemotherapy 54, 3702-3707. Marchand, S., Gregoire, N., Brillault, J., Lamarche, I., Gobin, P., Couet, W., 2015. Biopharmaceutical Characterization of Nebulized Antimicrobial Agents in Rats: 3. Tobramycin. Antimicrobial agents and chemotherapy 59, 6646-6647. 
Marchand, S., Gregoire, N., Brillault, J., Lamarche, I., Gobin, P., Couet, W., 2016. Biopharmaceutical Characterization of Nebulized Antimicrobial Agents in Rats. Antimicrobial agents and chemotherapy. Marchbanks, C.R., 1993. Drug-drug interactions with fluoroquinolones. Pharmacotherapy 13, 23S$28 \mathrm{~S}$.

434 Seedher, N., Agarwal, P., 2010. Effect of metal ions on some pharmacologically relevant interactions involving fluoroquinolone antibiotics. Drug metabolism and drug interactions 25, 17-24. Stass, H., Weimann, B., Nagelschmitz, J., Rolinck-Werninghaus, C., Staab, D., 2013. Tolerability and pharmacokinetic properties of ciprofloxacin dry powder for inhalation in patients with cystic fibrosis: a phase I, randomized, dose-escalation study. Clinical therapeutics 35, 1571-1581. Stohs, S.J., Bagchi, D., 1995. Oxidative mechanisms in the toxicity of metal ions. Free radical biology \& medicine 18, 321-336.

441 Stojkovic, A., Tajber, L., Paluch, K.J., Djuric, Z., Parojcic, J., Corrigan, O.I., 2014. Biopharmaceutical characterisation of ciprofloxacin-metallic ion interactions: comparative study into the effect of aluminium, calcium, zinc and iron on drug solubility and dissolution. Acta pharmaceutica 64, 77-88. Tewes, F., Brillault, J., Lamy, B., O'Connell, P., Olivier, J.C., Couet, W., Healy, A.M., 2015. Ciprofloxacin-loaded inorganic-organic composite microparticles to treat bacterial lung infection. Molecular pharmaceutics. Uivarosi, V., 2013. Metal complexes of quinolone antibiotics and their applications: an update. Molecules (Basel, Switzerland) 18, 11153-11197. 


\begin{tabular}{lll}
\hline \multicolumn{3}{l}{ Apparent association constant $\mathrm{K}\left(\mathrm{M}^{-1}\right)$} \\
\hline $\mathrm{Ca}^{2+}$ & $\mathbf{1} \times 10^{2}$ & {$[13-188]$} \\
$\mathrm{Mg}^{2+}$ & $\mathbf{7 . 2} \times 10^{2}$ & {$[176-1272]$} \\
$\mathrm{Zn}^{2+}$ & $\mathbf{2 7} \times 10^{2}$ & {$[1792-3614]$} \\
$\mathrm{Al}^{3+}$ & $\mathbf{8 8 0 \times 1 0 ^ { 2 }}$ & {$[56540-119406]$} \\
$\mathrm{Cu}^{2+}$ & $9069 \times 10^{2}$ & {$[849417-964359]$} \\
\hline
\end{tabular}

454 Table 1. Apparent association constant between CIP and ions (with the $95 \%$ confidence interval) in 455 saline solution at $\mathrm{pH} 7.4$.

Calu-3 cell toxicity EC50 $(\mu \mathrm{M})$

\begin{tabular}{|c|c|c|c|c|}
\hline & & & CIP & 7 [5-11] \\
\hline $\mathrm{Ca}^{2+}$ & $36 \times 10^{3}$ & {$\left[22-61 \times 10^{3}\right]$} & $\mathrm{CIP}: \mathrm{Ca}^{2+}$ & 5 [4-6] \\
\hline $\mathbf{M g}^{2+}$ & $131 \times 10^{3}$ & {$\left[111-152 \times 10^{3}\right]$} & CIP:Mg ${ }^{2+}$ & 11 [8-14] \\
\hline $\mathrm{Zn}^{2+}$ & $0.9 \times 10^{3}$ & {$\left[0.7-1.1 \times 10^{3}\right]$} & CIP: $: \mathbf{n}^{2+}$ & $3[3-4]$ \\
\hline $\mathbf{A l}^{3+}$ & $1.0 \times 10^{3}$ & {$\left[0.7-1.4 \times 10^{3}\right]$} & CIP:Al| $\left.\right|^{3+}$ & 7 [5-9] \\
\hline $\mathrm{Cu}^{2+}$ & $1.1 \times 10^{3}$ & {$\left[0.7-1.5 \times 10^{3}\right]$} & CIP:Cu${ }^{2+}$ & $14[12-16]$ \\
\hline
\end{tabular}

458 Table 2. Cell toxicity EC50 of cations alone or CIP:cations mix in 80\% complexation conditions over a $45924 \mathrm{~h}$ incubation period. Values are given with their $95 \%$ confidence interval.

460

461

462 
A

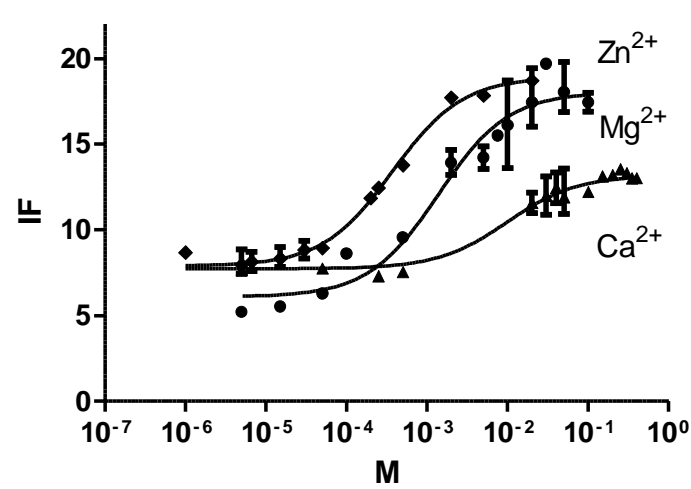

B

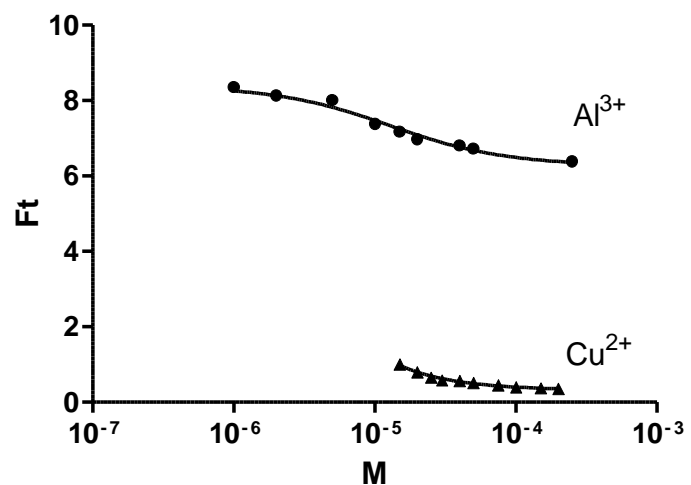

464

465

466

467

468

469

Figure 1. Titration curve of the total fluorescence against the molar concentration of ions. $3 \mu \mathrm{M}$ of $\mathrm{CIP}$ were mixed with increasing concentrations of $\mathrm{Mg}^{2+}, \mathrm{Ca}^{2+}, \mathrm{Zn}^{2+}(\mathrm{A}), \mathrm{Al}^{3+}$ or $\mathrm{Cu}^{2+}(\mathrm{B})$. Total fluorescence $(\mathrm{Ft})$ has been recorded at $\lambda$ exc $=274 \mathrm{~nm}$ and $\lambda e m=408 \mathrm{~nm}$. Data are expressed as means \pm range $(n=2-3)$ and were fitted with the 1:1 complex model.

A

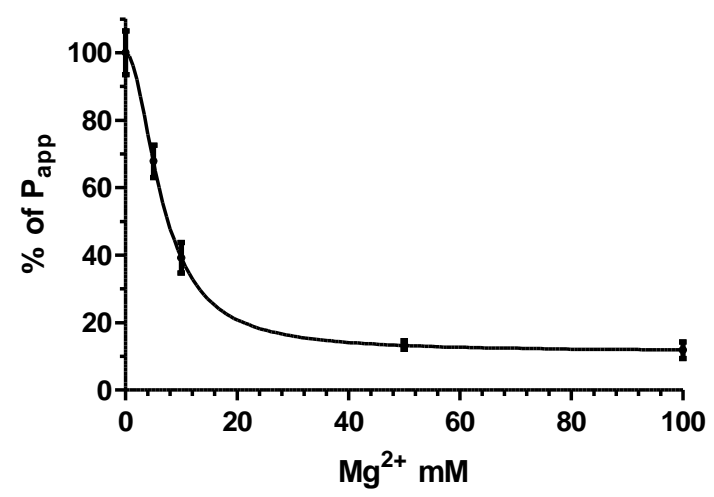

B

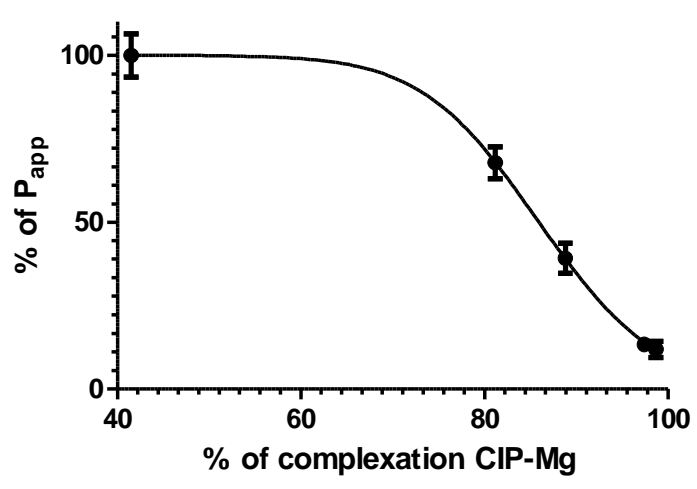

470

471

472

473

474

475

476

477

478

479

Figure 2. Influence of added $\mathrm{Mg}^{2+}$ concentration and $\mathrm{Mg}$-complexation on the apparent permeability for CIP. The apical-to-basolateral permeability of the Calu-3 cell layer for CIP ( $50 \mu \mathrm{M})$ was evaluated in the presence of increasing concentrations of $\mathrm{Mg}^{2+}(\mathrm{A})$. Permeability was also plotted against the \% of complexation calculated with the constant of association between CIP and $\mathrm{Mg}^{2+}(\mathrm{B})$. Results were expressed as a the percentage of the CIP Papp $\left(0.34 \pm 0.02 \times 10^{-6} \mathrm{~cm} / \mathrm{s}\right)$ determined with no $\mathrm{Mg}^{2+}$ added to the transport medium (means \pm S.E.M., $\mathrm{n}=3$ ). 


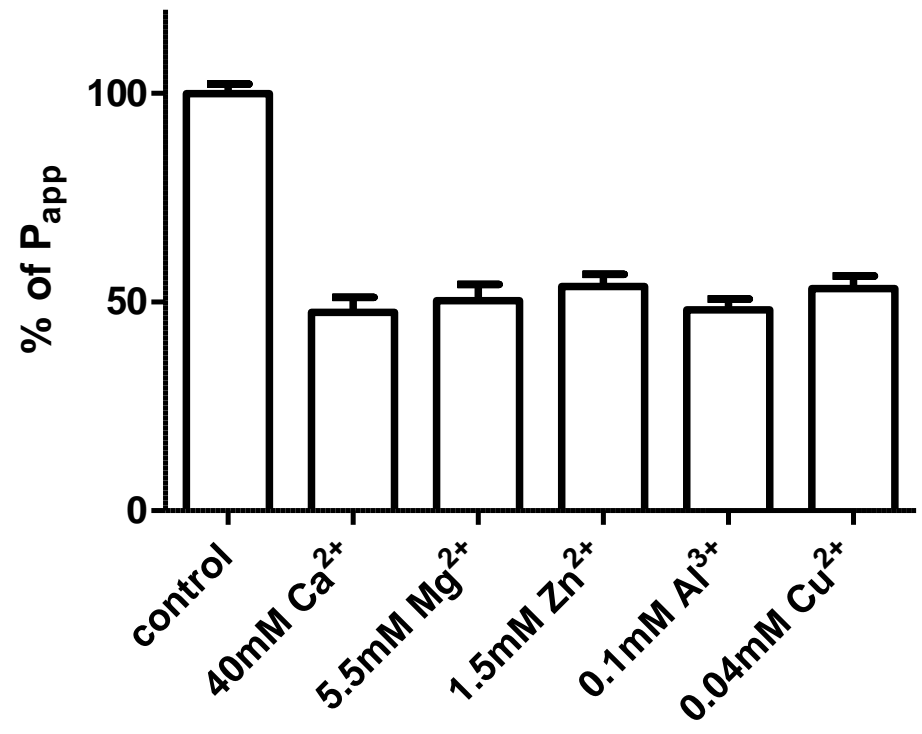

480

Figure 3. Papp of CIP in conditions of $80 \%$ complexation. $50 \mu \mathrm{M}$ of CIP were incubated with adequate concentrations of $\mathrm{Ca}^{2+}, \mathrm{Mg}^{2+}, \mathrm{Zn}^{2+}, \mathrm{Al}^{3+}$ or $\mathrm{Cu}^{2+}$ ions to achieve a proportion of $80 \%$ of CIP:metal cation complexation in solution. Data are expressed as the percentage of the control Papp for $\mathrm{CIP}$ (means \pm S.E.M., $\mathrm{n}=8$ to 12 ). Each condition was significantly different from control using one-way ANOVA and Bonferroni's post hoc test $(P<0.001)$.

487

488

489

490

491

492

493

494

495

496

497

498 
A

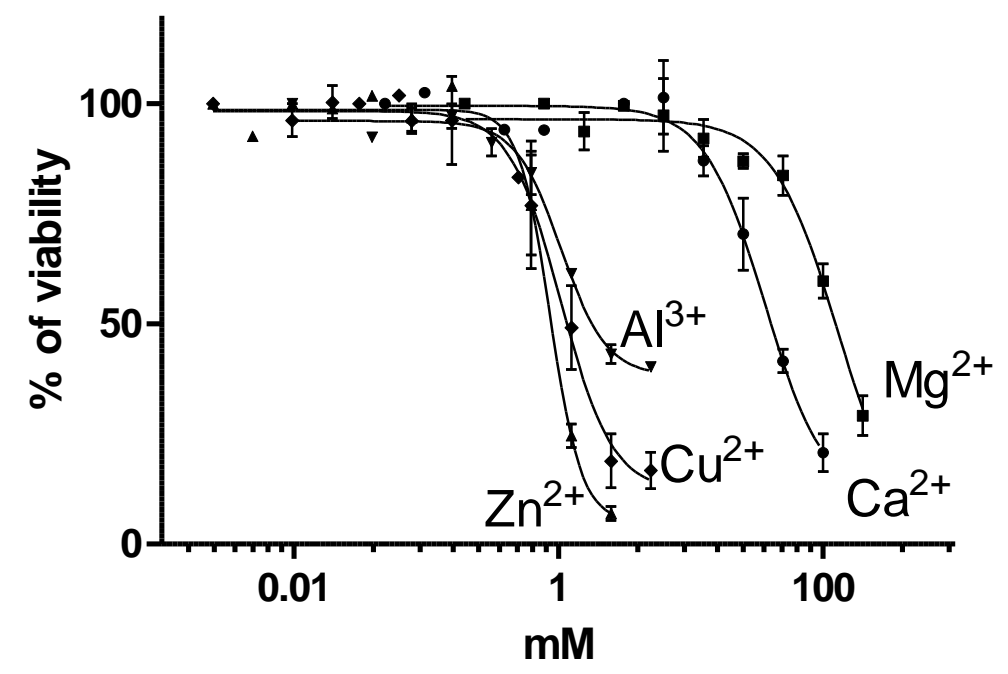

B

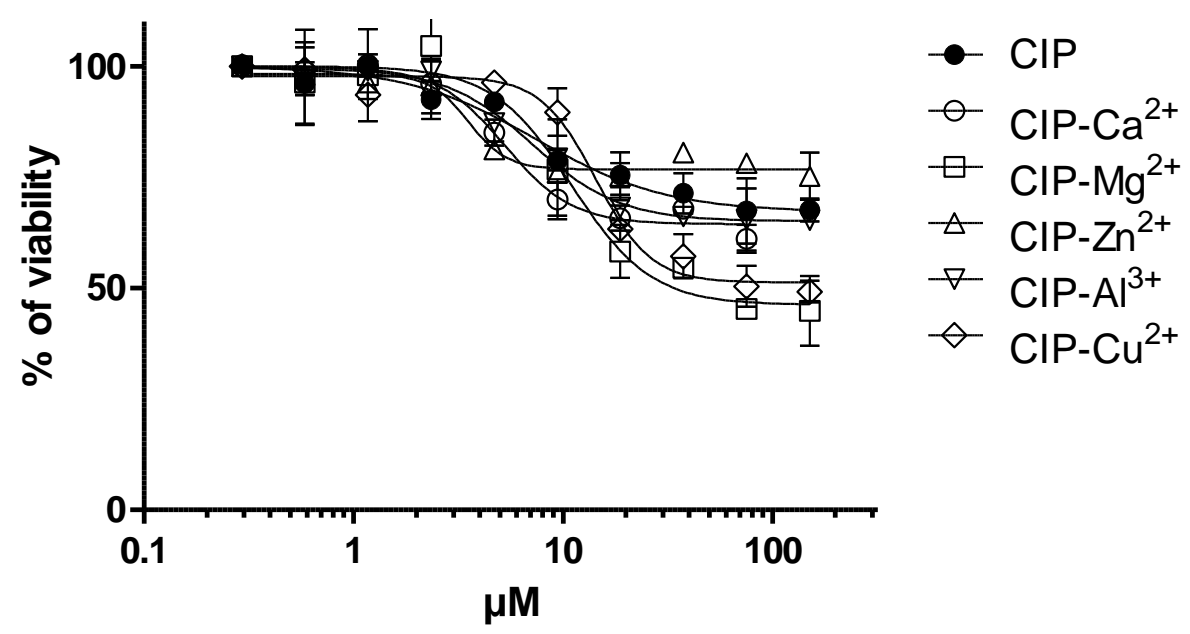

Figure 4. Toxicity of CIP, ions or CIP:ions complexes on Calu-3 cells. Cells were incubated for $24 \mathrm{~h}$ with different concentrations of cations (A) and different concentrations of CIP in the presence of cations (B). Cytotoxicity was evaluated with MTS test kit. 100\% correspond to the control condition 
A

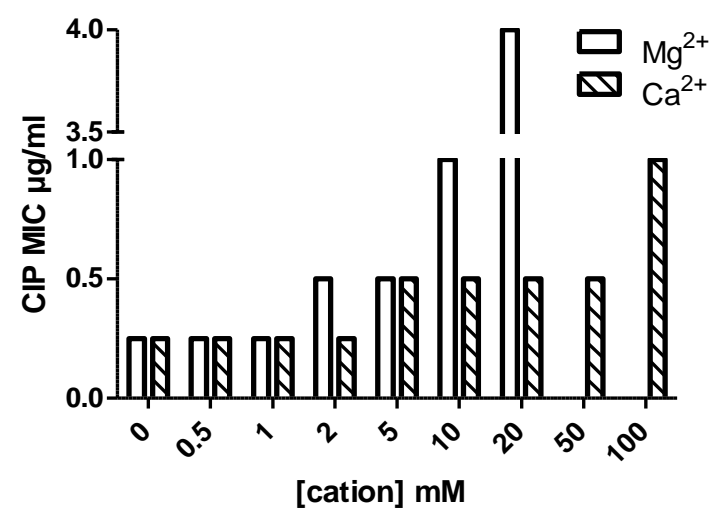

B

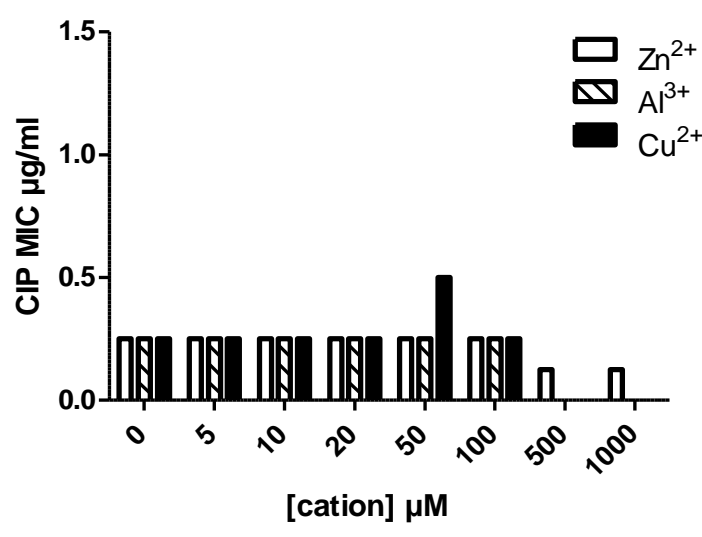

507

508

509

510

511

512

513

514

515

516
Figure 5. CIP apparent MIC against $P$. aeruginosa in Mueller-Hinton broth II in the presence of increasing concentrations of $\mathrm{Ca}^{2+}, \mathrm{Mg}^{2+}(\mathrm{A}), \mathrm{Zn}^{2+}, \mathrm{Al}^{3+}$ or $\mathrm{Cu}^{2+}(\mathrm{B})$. MICs represent non-continuous data and are accurate to only plus or minus one two-fold dilution. 


\section{Appendix A.}

518 For 1:1 complex (CIP:I) between ciprofloxacin (CIP) and a metal ion (I), the equilibrium,

519 apparent binding constant $\mathrm{K}$ and mass balance equations are expressed in eqn (1)-(4).

$520 \quad \mathrm{CIP}+\mathrm{I} \leftrightarrows \mathrm{CIP}: \mathrm{I}$

$521 \quad \mathrm{~K}=\frac{[C I P: I]}{[C I P][I]}$

$522[C I P] \mathrm{t}=[C I P]+[C I P: I]$

$523 \quad[I] \mathrm{t}=[I]+[C I P: I]$

524 Where [CIP]t and [I]t are the the concentrations of the total CIP and metal ions and [CIP] and

$525[\mathrm{I}]$ are the concentrations of the free CIP and metal ions. [CIP:I] is the concentration of the

526 complexe. Rearranging eqn (2) with eqn (3) and (4) yields to the quadratic equation (5) from

527 which the eqn (6) is a solution.

$528[C I P]^{2}+\left([I] \mathrm{t}-[C I P] \mathrm{t}+\frac{1}{\mathrm{~K}}\right)[C I P]-\frac{[C I P] \mathrm{t}}{\mathrm{K}}=0$

$529 \quad[C I P]=\frac{-\left([I] \mathrm{t}-[C I P] \mathrm{t}+\frac{1}{\mathrm{~K}}\right)+\sqrt{\left([I] \mathrm{t}-[C I P] \mathrm{t}+\frac{1}{\mathrm{~K}}\right)^{2}+\frac{4[C I P] \mathrm{t}}{\mathrm{K}}}}{2}$

530 The observed fluorescence (Ft) is the sum of the CIP and CIP:I complex fluorescences (FCIP

531 and FCIP:I), considering the ions are not fluorescent:

$532 F t=F C I P+F C I P: I=\delta \operatorname{CIP}[C I P]+\delta C I P: I[C I P: I]$

533 where $\delta \mathrm{CIP}$ and $\delta \mathrm{CIP}: \mathrm{I}$ are the proportionality coefficients between concentration and

534 fluorescence for the CIP and the complex respectively. Rearranging eqn (7) with eqn (3) and

535 into eqn (6) gives the final 1:1 binding isotherm (eqn 8). 


$$
F t=(\delta \operatorname{CIP}-\delta \operatorname{CIP}: \mathrm{I})\left\{\frac{\left([C I P] \mathrm{t}-[I] \mathrm{t}-\frac{1}{\mathrm{~K}}\right)+\sqrt{\left([I] \mathrm{t}-[C I P] \mathrm{t}+\frac{1}{\mathrm{~K}}\right)^{2}+\frac{4[C I P] \mathrm{t}}{\mathrm{K}}}}{2}\right\}+\delta \operatorname{CIP}: \mathrm{I}[C I P] \mathrm{t}
$$

538 For 2:1 complex (CIP2:I) between ciprofloxacin (CIP) and a metal ion (I), the equilibriums,

539 binding constants K1 and K2 and mass balance equations are expressed in eqn (9)-(14). For

540 eqn (14), the assumption that the initial concentration of ions ([I]t) is much higher than the

541 initial concentration of CIP ([CIP]t) leads to a simplified equation. Experimentally, ion

542 concentrations were always at least 5 times higher than CIP.

$543 \mathrm{CIP}+\mathrm{I} \leftrightarrows \mathrm{CIP}: \mathrm{I}$

$544 \quad \mathrm{CIP}: \mathrm{I}+\mathrm{CIP} \leftrightarrows \mathrm{CIP} 2: \mathrm{I}$

$545 \quad \mathrm{~K} 1=\frac{[C I P: I]}{[C I P][I]}$

$546 \quad \mathrm{~K} 2=\frac{[C I P 2: I]}{[C I P: I][C I P]}$

$547 \quad[C I P] \mathrm{t}=[C I P]+[C I P: I]+2[C I P 2: I]$

$548 \quad[I] \mathrm{t}=[I]+[C I P: I]+[C I P 2: I] \approx[I]$

549 Rearranging eqn (11) and (12) with eqn (13) and (14) yields to the quadratic equation (15)

550 from which the eqn (16) is a solution.

$551 \quad[C I P]^{2}+\left(\frac{1+\mathrm{K} 1[I] \mathrm{t}}{2 \mathrm{~K} 1 \mathrm{~K} 2[I] \mathrm{t}}\right)[C I P]-\frac{[C I P] t}{2 \mathrm{~K} 1 \mathrm{~K} 2[I] \mathrm{t}}=0$

$552[C I P]=\frac{-\left(\frac{1+\mathrm{K} 1[I] \mathrm{t}}{2 \mathrm{~K} 1 \mathrm{~K} 2[] \mathrm{t}}\right)+\sqrt{\left(\frac{1+\mathrm{K} 1[I] \mathrm{t}}{2 \mathrm{~K} 1 \mathrm{~K} 2[I] \mathrm{t}}\right)^{2}+\frac{2[C I P] \mathrm{K}}{\mathrm{K} 1 \mathrm{~K} 2[I] \mathrm{t}}}}{2}$ 
553 The observed fluorescence (Ft) is the sum of the CIP, CIP:I and CIP2:I complex fluorescences

554 (FCIP, FCIP:I and FCIP2:I), considering that the ions are not fluorescent:

$555 F t=F C I P+F C I P: I+F C I P 2: I=\delta C I P[C I P]+\delta C I P: I[C I P: I]+\delta C I P 2: I[C I P 2: I]$

556 where $\delta$ CIP $, \delta C I P: I$ and $\delta C I P 2: I$ are the proportionality coefficients between concentration

557 and fluorescence for the CIP and the complexes. Rearranging eqn (17) with eqn (11) and (12)

558 gives the final 2:1 binding isotherm (eqn 18) together with eqn (16).

$559 F t=\left(\delta \mathrm{CIP}+\delta \mathrm{CIP}: \mathrm{I} \mathrm{K} 1[I \mathrm{t})[C I P]+\delta \mathrm{CIP} 2: \mathrm{I} \mathrm{K} 1 \mathrm{~K} 2\left[I \mathrm{t}[C I P]^{2}\right.\right.$

560

561 